\title{
A Case Report of Obsessive-Compulsive Disorder and Complete Remission of Schizophrenia
}

\author{
Nusrat Shamima Nur ${ }^{*}$ and Kabirul Hasan Bin Rakib ${ }^{2}$ \\ ${ }^{1}$ Department of Psychiatry, Bangabandhu Sheikh Mujib Medical University, Dhaka, Bangladesh \\ ${ }^{2}$ Department of Internal Medicine, Bangabandhu Sheikh Mujib Medical University, Dhaka, Bangladesh
}

*Corresponding author: Nusrat Shamima Nur, Resident Doctor of Child and Adolescent Psychiatry, Department of Psychiatry, Bangabandhu Sheikh Mujib Medical University, Dhaka, Bangladesh, Tel: +8801767882843; E-mail: nusratshamimanur@gmail.com

\begin{abstract}
A 21-year-old lady who is previously diagnosed as a case of Schizophrenia, 4 years back, with positive symptoms such as delusion, hallucination. She has prescribed with risperidone $4 \mathrm{mg}$ and she is compliant to drug. Currently she is on full remission for 1 year. She is under treatment with Risperidon, $4 \mathrm{mg}$. This lady has some complaints of obsessions such as aggressive impulses and pathological doubt which is followed by some compulsions such as avoidance and checking rituals for last 3 years. She has complained of having some experiences such as doing something embarrassing and these experiences are truly intrusive, unwanted and senseless to her. This currently remitted Schizophrenic patient has good insight now. She has a marked improvement in her daily activities as well as sociability.
\end{abstract}

Keywords: Schizophrenia; Resistive index; Obsessive compulsive disorder; Hallucination

Received Date: January 23, 2019; Accepted Date: February 15, 2019; Published Date: February 22, 2019

\section{Background}

Obsessive compulsive (OC) symptoms in schizophrenia have been described in various forms as a part of the schizophrenic phenomena for over a century. The OC symptoms in patients with schizophrenia may take on varied clinical presentations, such as contamination, sexual, religious, aggressive, or somatic themes, with or without accompanying compulsions, such as cleaning, checking, hoarding, repeating, or arranging. Early clinicians, such as Westphal, Kraepelin, Stengel and Bleuler considered such OC phenomena as either a prodrome or an integral part of the schizophrenic illness. Unfortunately, there has since been little progress in our understanding of the clinical and neurobiological significance of OC phenomenon in schizophrenia. Obsessive Compulsive Disorder can present with obsession such as contamination obsession, somatic obsession, aggressive obsession, sexual obsession, religious obsession, hoarding or saving obsession, pathological doubt, obsession with need for symmetry/exactness and other obsession and compulsion such as cleaning/washing compulsion, checking compulsion, repeating rituals, counting compulsion, ordering/arranging compulsions, hoarding/collecting compulsion, etc. Schizophrenia Citation: Nusrat Shamima Nur, A Case Report of Obsessive Compulsive Disorder and Complete Remission of Schizophrenia. J Clin Cases Rep 2(2): 57-59. DOI: https://doi.org/10.46619/joccr.2019.2-1039 
http://www.tridhascholars.org | April-2019

can present with delusions, hallucinations, disorganized behavior, disorganized speech and negative symptoms such as alogia, anhedonia, social withdrawal, avolition, affective instability.

\section{Introduction}

Schizophrenia is included in Schizophrenia Spectrum and Other Psychotic Disorder in Diagnostic and Statistical Manual of Mental Disorder, 5th edition and Obsessive Compulsive Disorder is included in Obsessive Compulsive and Related Disorder in Diagnostic and Statistical Manual of mental disorder, $5^{\text {th }}$ edition. Schizophrenia is a psychosis and Obsessive Compulsive Disorder is neurosis but before diagnosis of Schizophrenia of an individual, a person can present with symptoms of Obsessive Compulsive Disorder. In this case, a woman of twenty-one years old, married, right handed has diagnosed as Obsessive Compulsive Disorder and complete remission of Schizophrenia.

\section{Case Report}

A 21-year-old, married, right handed woman, belongs from middle class socio-economic condition hailing from Dhaka Bangladesh has presented me with the complaints of persistent and repetitive aggressive impulse for 3 years followed by avoidance, persistent and repetitive thought of doubt followed by checking for 1 year. According to the statement of the patient that she was relatively well 3 years back then she starts fear of doing something embarrassing such as when talks with anyone she thinks that her eyes direction goes to the sensitive organs of both male and female such as breast and genitalia. It is completely intrusive, unwanted and non-sense. She wants to suppress or avoid it. So she avoids talking to people by maintaining eye contact. Then for last 1 year she starts persistent and repetitive thought of doubt of performing daily routine activities or not even after completing daily routine activities, which is followed by checking locks, stoves, appliances. This thinking and rituals cause significant impairment of her social activities, such as wastage of more than 1 hour daily. For psychiatric evaluation she has visited to psychiatric OPD of Bangabandhu Sheikh Mujib Medical University. In her past psychiatric illness she has diagnosed as a case of Schizophrenia. Evaluation of the symptoms of the past psychiatric condition of Schizophrenia, she had presented with $3^{\text {rd }}$ person hallucinations which is real, vivid, in presence of another real sensations, having real perceptual quality and cannot be terminated at will, to her. In her experience to hallucinations that hallucinatory voices were criticizing the activities of her and voices were known to her. She had also delusion of reference, delusion of persecution. Her activities of daily life were markedly impaired. After diagnosing Schizophrenia she has prescribed with Risperidon $4 \mathrm{mg}$ and Diazepam $10 \mathrm{mg}$. She is compliant to drug. Her positive symptoms are remitted for last 1 year. Her premorbid personality reveals that she is sociable to friends, family and relatives. Her predominant mood is euthymic. Her character is optimistic. She is moral and religious. She watches television in her leisure period. General examination and systemic examination reveals normal. In her mental state examination an approximately a middle aged woman with average body built and average nutritional state sat on the chair. She was well dressed, well kempt, well combed and her dress up was socio-culturally accepted. Facial expression was normal. Rapport was established and maintained. There were no abnormalities in posture and movement. No abnormalities in social and motor behavior. Mood was euthymic and affect was congruent. Rate, rhythm, flow, tone, volume was normal. There were no oddities of speech. There was presence of obsession and compulsion but no other thought abnormalities. There were no perceptual abnormalities. She was well conscious, oriented to time, place and person. Attention was sustained and she was well concentrated. Memory was intact, intelligence was average, and judgment and insight were intact. Laboratory investigation shows that her haemoglobin: $11.4 \mathrm{gm} / \mathrm{dl}$, ESR: $15 \mathrm{~mm}$ in $1^{\text {st }}$ hour, RBC: $3.8 \mathrm{million} / \mathrm{cubic} \mathrm{mm}$, PCV: 0.3 l/l, MCV: 88.0 fl, MCH: 29.0 pg, MCHC: 33 GM/dl, RDW (CV): 11\%, MPV: 8.1 fl, PDW: 12.0 fl, random blood glucose: $4.3 \mathrm{mmol} / \mathrm{L}$, ALT: $18 \mathrm{U} / \mathrm{L}$, Creatinine: $0.56 \mathrm{mg} / \mathrm{dl}$. 
http://www.tridhascholars.org | April-2019

\section{Conclusion}

Schizophrenia with complete remission can occur in approximately $1 / 6^{\text {th }}$ of the patients. Here complete remission of Schizophrenia has done with this patient. Some behaviors of patient which can be disorganized in schizophrenia but it can present with aggressive obsession. In this particular case, patient has presented with aggressive obsession.

\section{Discussion}

The lifetime prevalence for schizophrenia is $1 \%$ and for OCD it is $2 \%$ to $3 \%$. Comorbidity rates for OCD in the schizophrenia population are substantially higher than what would be expected to occur randomly. In the schizophrenic population, the reported prevalence of clinically significant OCS and of OCD ranges from 10\% to 52\% and from $7.8 \%$ to $26 \%$, respectively. The presence of prior diagnosis of OCD was associated with an increased risk of developing schizophrenia (IRR $=6.90 ; 95 \%$ CI, 6.25-7.60) and schizophrenia spectrum disorders (IRR $=5.77$; 95\% CI, 5.33-6.22) later in life. Similarly, offspring of parents diagnosed as having OCD had an increased risk of schizophrenia (IRR $=4.31$; 95\% CI, 2.72-6.43) and schizophrenia spectrum disorders (IRR $=3.10 ; 95 \% \mathrm{CI}, 2.17-4.27$ ). The results remained significant after adjusting for family history of psychiatric disorders and the patient's psychiatric history.

Conflict of Interest: The author declares they have no conflict of interest.

\section{References}

1. Hwang MY, Yum SY, Losonczy MF, et al. (2006) Schizophrenia with obsessive compulsive features. Psychiatry (Edgmont) 3(9): 34-41.

2. Bottas A (2009) Comorbidity: Schizophrenia with obsessive-compulsive disorder. Psychiatric Times 26(4): 1-2.

3. Meier SM, Petersen L, Pedersen MG, et al. (2014) Obsessive-compulsive disorder as a risk factor for schizophrenia: a nationwide study. JAMA Psychiatry 71(11): 1215-1221.

4. https://www.psychiatry.org/psychiatrists/practice/dsm

5. https://psychres.washington.edu/clinicaltools/ybocs.pdf 